\title{
COMMENTARY
}

\section{Early hemodynamic resuscitation in septic shock: understanding and modifying oxygen delivery}

\author{
Paul A van Beest ${ }^{1 *}$ and Peter E Spronk ${ }^{2}$ \\ See related research by Ospina-Tascón et al., http://ccforum.com/content/17/6/R294
}

\begin{abstract}
In a previous issue of Critical Care, researchers have focused on the venous-to-arterial carbon dioxide difference $\left(\mathrm{Pv}-\mathrm{aCO} \mathrm{CO}_{2}\right)$ as a surrogate marker for systemic perfusion in patients with septic shock. Although the complex mechanisms responsible for an increased $\mathrm{Pv}_{\mathrm{aCO}}$ in septic shock need to be further unraveled, the potential prognostic value of $\mathrm{Pv}-\mathrm{aCO}_{2}$ seems clinically relevant and useful in daily practice in view of its easy availability.
\end{abstract}

The resuscitation of patients with sepsis remains a challenging task. In the presence of shock, early optimization of global and regional perfusion mandates adequate monitoring. Whatever kind of monitoring is used, it should provide reliable information with potential therapeutic and prognostic relevance. In a previous issue of Critical Care, Ospina-Tascón and colleagues [1] describe a potentially useful tool as a target for resuscitating early septic shock. The Surviving Sepsis Campaign guidelines for early hemodynamic optimization recommend normalization of central venous oxygen saturation $\left(\mathrm{ScvO}_{2}\right)$ [2]. $\mathrm{ScvO}_{2}$ reflects the imbalance between oxygen delivery $\left(\mathrm{DO}_{2}\right)$ and oxygen demand $\left(\mathrm{VO}_{2}\right)$. However, in the majority of patients with severe sepsis or septic shock who are acutely admitted to the $\mathrm{ICU}, \mathrm{ScrO}_{2}$ values are normal or elevated (>70\%) [3]. Hence, an additional circulatory parameter is needed to evaluate resuscitation efforts.

Ospina-Tascón and colleagues [1] have focused on the venous-to-arterial carbon dioxide difference $\left(\mathrm{Pv}-\mathrm{aCO}{ }_{2}\right)$ as a surrogate marker for systemic perfusion in patients with septic shock. This could make sense. Indeed, $\mathrm{Pv}_{\mathrm{aCO}}$ may be used to mathematically calculate cardiac index [4].

\footnotetext{
* Correspondence: p.van.beest@umcg.nl

'Department of Anesthesiology, University Medical Center Groningen,

University of Groningen, Hanzeplein 1, Groningen 9700 RB, The Netherlands Full list of author information is available at the end of the article
}

In addition, a cutoff value for $\mathrm{Pv}-\mathrm{aCO} 2$ of $6 \mathrm{~mm} \mathrm{Hg}$ may be used to discriminate between high and low lactate clearance and cardiac index in critically ill patients who were seemingly resuscitated [5].

In a prospective observational study, Ospina-Tascón and colleagues [1] classify their patient population into four predefined groups based on the evolution of $\mathrm{Pv}-\mathrm{aCO}_{2}$ during the first 6 hours of resuscitation. $\mathrm{A} \mathrm{Pv}-\mathrm{aCO}_{2}$ of at least $6 \mathrm{~mm} \mathrm{Hg}$ was considered high $(\mathrm{H})$, and a $\mathrm{Pv}-\mathrm{aCO}_{2}$ of less than $6 \mathrm{~mm} \mathrm{Hg}$ was considered normal or low (L). Their results show that two groups have better outcome: that is, patients with low $\mathrm{Pv}-\mathrm{aCO} 2$ throughout the observational period (LL) and patients in whom $\mathrm{Pv}-\mathrm{aCO}_{2}$ decreased from high to low values (HL) [1]. The patients in the first group were either less severely ill or already adequately volume-resuscitated before ICU admission. Analogously to earlier findings [5], the HL patients may be considered responders to treatment mirrored by the significant lactate clearance from 2.7 to $1.3 \mathrm{mmol} / \mathrm{L}$. In contrast, persistently high $\mathrm{Pv}-\mathrm{aCO}{ }_{2}$ values $(\mathrm{HH})$ or increasing $\mathrm{Pv}-\mathrm{aCO}_{2}$ values (LH) predicted worse outcome. The patients in the $\mathrm{HH}$ group were too severely ill, and during treatment for the patients in the LH group a substantial oxygen debt was probably recognized too late. In addition, an increased mortality risk was observed when patients reached an $\mathrm{ScvO}_{2}$ of at least $70 \%$ with concomitantly high $\mathrm{Pv}-\mathrm{aCO}_{2}$ values. This is in line with recent findings that $\mathrm{Pv}-\mathrm{aCO}_{2}$ may be used as triage tool when $\mathrm{ScvO}_{2}$ values are more than $70 \%$ on ICU admission [5,6]. Hence, $\mathrm{Pv}_{-} \mathrm{aCO}_{2}$ may potentially be of prognostic value. In addition, $\mathrm{Pv}-\mathrm{aCO}_{2}$ values can be easily obtained with low costs, making this parameter potentially clinically relevant and useful in daily practice.

Nevertheless, one has to bear in mind that the mechanisms responsible for an increased $\mathrm{Pv}-\mathrm{aCO}_{2}$ in patients with septic shock are not fully understood yet. On the microcirculatory level, distributive changes may be independent of cardiac output (CO) [7]. This means that on a regional level, in accordance with the possibility of 
persistent hypoxia despite normal $\mathrm{ScvO}_{2}$ levels, the accumulation of carbon dioxide $\left(\mathrm{CO}_{2}\right)$ occurs in microcirculatory weak units, despite adequate $\mathrm{CO}$. However, $\mathrm{Pv}_{\mathrm{v}} \mathrm{aCO}_{2}$ reflects the ability to wash out the accumulated $\mathrm{CO}_{2}$ better than the presence of anaerobic metabolism $[7,8]$. Also, an increased $\mathrm{Pv}-\mathrm{aCO}_{2}$-to- $\mathrm{VO}_{2}$ ratio could reflect global anaerobic metabolism [9], and the ratio of $\mathrm{Pv}-\mathrm{aCO}_{2}$ divided by arteriovenous oxygen content difference predicts an increase of oxygen utilization after a fluid-induced increase in $\mathrm{DO}_{2}$ [10]. This means that $\mathrm{Pv}-\mathrm{aCO}$ values may also be of therapeutic relevance. A decrease of heterogeneity of the microcirculation may potentially result in an increased $\mathrm{CO}_{2}$ washout and a decreased $\mathrm{Pv}-\mathrm{aCO} \mathrm{CO}_{2}$-to- $\mathrm{VO}_{2}$ ratio. Also, the balance between $\mathrm{DO}_{2}$ and $\mathrm{VO}_{2}$ may be restored. It is tempting to hypothesize that the necessary improved recruitment of microcirculation in the early resuscitation phase may be achieved by the use of vasodilatators in addition to volume loading [11,12]. Indeed, the results of Ospina-Tascón and colleagues may provide an argument to implement vasodilators within 6 hours, which probably could be stopped after recruitment has occurred. Such a strategy may be particularly beneficial to septic shock patients resembling the patients described in the LH group.

In conclusion, $\mathrm{Pv}-\mathrm{aCO}_{2}$ provides us with additional information to hemodynamic and oxygen-derived parameters currently used in the resuscitation of patients with sepsis. $\mathrm{Pv}-\mathrm{aCO}_{2}$ values seem clinically relevant and are potentially of prognostic value.

\footnotetext{
Abbreviations

$\mathrm{CO}$ : Cardiac output; $\mathrm{CO}_{2}$ : Carbon dioxide; $\mathrm{DO}_{2}$ : Oxygen delivery; $\mathrm{HH}$ group: Patients with persistently high venous-to-arterial carbon dioxide difference values; HL group: Patients with decreasing venous-to-arterial carbon dioxide difference values; LH group: Patients with increasing venous-to-arterial carbon dioxide difference values; LL group: Patients with persistently low venous-to-arterial carbon dioxide difference values; $\mathrm{Pv}$-aCO : Venous-to-arterial carbon dioxide difference; $\mathrm{ScvO}_{2}$ : Central venous oxygen saturation;

$\mathrm{VO}_{2}$ : Oxygen demand.
}

\section{Competing interests}

The authors declare that they have no competing interests.

\section{Author details}

'Department of Anesthesiology, University Medical Center Groningen, University of Groningen, Hanzeplein 1, Groningen 9700 RB, The Netherlands. ${ }^{2}$ Department of Intensive Care Medicine, Gelre Hospitals Apeldoorn, Albert Schweitzerlaan 31, Apeldoorn 7300 DS, The Netherlands.

Published: 18 Feb 2014

\section{References}

1. Ospina-Tascón GA, Bautista-Rincón DF, Umaňa M, Tafur JD, Gutiérrez A, García AF, Bermúdez W, Granados M, Arango-Dávila C, Hernández G: Persistently high venous-to-arterial carbon dioxide differences during early resuscitation are associated with poor outcomes in septic shock. Crit Care 2013, 17:R294.

2. Dellinger RP, Levy MM, Rhodes A, Annane D, Gerlach H, Opal SM, Sevransky JE, Sprung C: Surviving Sepsis Campaign: international guidelines for management of severe sepsis and septic shock, 2012. Intensive Care Med 2013, 39:165-228.
3. van Beest PA, Hofstra JJ, Schultz MJ, Boerma EC, Spronk PE, Kuiper MA: The incidence of low venous oxygen saturation on admission in the ICU: a multicenter observational study in the Netherlands. Crit Care 2008, 12:R33.

4. Cuschieri J, Rivers EP, Donnino MW, Katilius M, Jacobson G, Nguyen HB, Pamukov N, Horst HM: Central venous-arterial carbon dioxide difference as an indicator of cardiac index. Intensive Care Med 2012, 31:818-822.

5. Vallée F, Vallet B, Mathe O, Parraguette J, Mari A, Silva S, Samii K, Fourcade O, Genestal M: Central venous-to-arterial carbon dioxide difference: an additional target for goal-directed therapy in septic shock? Intensive Care Med 2008, 34:2218-2225.

6. van Beest PA, Lont MC, Holman ND, Loef B, Kuiper MA, Boerma EC: Central venous-arterial $\mathrm{pCO}_{2}$ difference as a tool in resuscitation of septic patients. Intensive Care Med 2013, 39:1034-1039.

7. Creteur J, De Backer D, Sakr Y, Koch M, Vincent JL: Sublingual capnometry tracks microcirculatory changes in septic patients. Intensive Care Med 2006, 32:516-523.

8. Bakker J, Vincent JL, Gris P, Leon M, Coffernils M, Kahn RJ: Veno-arterial carbon dioxide gradient in human septic shock. Chest 1995, 101:509-515.

9. Mekontso-Dessap A, Castelein V, Anguel N, Bahloul M, Schauvliege F, Richard C, Teboul JL: Combination of venoarterial $\mathrm{PCO}_{2}$ difference with the arteriovenous $\mathrm{O}_{2}$ content difference to detect anaerobic metabolism in patients. Intensive Care Med 2002, 28:272-277.

10. Monnet X, Julien F, Ait-Hamou N, Lequoy M, Gosset C, Jozwiak M, Persichini R, Anguel N, Richard C, Teboul JL: Lactate and venoarterial carbon dioxide difference / arterial-venous oxygen difference ratio, but not central venous oxygen saturation, predict increase in oxygen consumption in fluid responders. Crit Care Med 2013, 41:1412-1420.

11. Bihari D, Smithies M, Gimson A, Tinker J: The effects of vasodilation with prostacyclin on oxygen delivery and uptake in critically ill patients. N Engl J Med 1987, 317:397-403.

12. Spronk PE, Ince C, Gardien MJ, Mathura KR, Oudemans-van Straaten HM, Zandstra DF: Nitroglycerin in septic shock after intravascular volume resuscitation. Lancet 2002, 360:1395-1396.

$10.1186 / \mathrm{cc} 13732$

Cite this article as: van Beest and Spronk: Early hemodynamic resuscitation in septic shock: understanding and modifying oxygen delivery. Critical Care 2014, 18:111 